\title{
Amyloidosis presenting as acute liver failure: a case report
}

Raj Parikh* and Christine S. Tsai

*Correspondence: raj_parikh@rush.edu

CrossMark

$\leftarrow$ Click for updates

Department of Internal Medicine, Rush University Medical Center, Chicago, IL, USA.

\begin{abstract}
Introduction: Amyloidosis has two principle types: multiple myeloma-associated (AL) and amyloidassociated amyloidosis (AA). Both types can be local or systemic and can often involve the liver. Hepatic amyloidosis carries a poor prognosis, but commonly presents with a more gradual time course of evolving hepatomegaly and elevated serum alkaline phosphatase. This casereport involves an unusual presentation of hepatic amyloidosis with acute liver decompensation resulting in death.

Case presentation: A 76 year old man presented with complaints of progressive weakness and anorexia resulting in weight loss. He was initially found to have laboratory abnormalities notable for cholestasis and a mild transaminitis. On exam, the patient was cachectic with scleral icterus, jaundice, and abdominal distention. Liver ultrasound with doppler imaging was significant for increased echogenicity of the liver and ascites. The patient underwent transjugular liver biopsy, which demonstrated hepatic amyloid. Additional testing revealed a diagnosis of amyloidosis secondary to multiple myeloma. On day 5 of the patient's admission, cholestasis and transaminitis acutely worsened, with eventual peaking of aspartate aminotransferase to $3362 \mathrm{u} / \mathrm{l}$, alanine aminotransferase to $1439 \mathrm{u} / \mathrm{l}$, and total bilirubin to $18.8 \mathrm{mg} / \mathrm{d}$. Further work-up for this acute decompensation, including imaging and laboratory tests, did not reveal any triggering events such as portal vein thrombosis or intra-abdominal bleeding from recent liver biopsy. Additionally, cardiovascular compromise, infectious etiologies, and toxins were ruled out. Unfortunately, the patient was not a candidate for chemotherapy given his acute hepatic decompensation and subsequent encephalopathy on day 8 of admission. The patient was started on Lactulose and $\mathrm{N}$-acetylcysteine, though his mental status continued to worsen and the patient died on day 10 of admission from multi-organ compromise secondary to acute liver failure.
\end{abstract}

Conclusion: Amyloidosis resulting in acute hepatic failure has previously been reported but remains quite rare. Clinicians must consider infiltrative diseases, such as multiple myeloma and amyloidosis, when patients present with an extended prodromal illness paired with unexplained, worsening hepatic dysfunction.

Likewise, physicians should be aware that patients who present with hepatic amyloid secondary to multiple myeloma are at high risk for rapid clinical deterioration.

Keywords: Amyloidosis, acute liver failure, multiple myeloma, ascites, biopsy, encephalopathy

\section{Introduction}

Amyloidosis has two principle types: multiple myeloma (MM)associated and amyloid-associated amyloidosis (AA). Amyloids are characterized as proteins that fold into insoluble deposits in organs and tissues, causing significant disruption of normal function. Meanwhile, MM is defined as a malignancy of white blood cells. In specific, plasma cells, which are responsible for producing antibodies, are malfunctioning in MM. Typically, these cells will aggregate in the bone marrow and also disrupt production of normal blood cells. MM often involves significant kidney injury, which is a result of paraprotein production. Bone lesions and high calcium levels are also common findings in the disease as well.

Both $A L$ and AA can present with involvement of the liver. Hepatic amyloidosis most commonly presents with hepatomegaly (81\%) and elevated serum alkaline phosphatase (86\%) though pancreatic infiltration has been seen as well [1-6]. In MM, plasma cell infiltration of the liver can be seen in up to $45 \%$ of patients $[9,10]$. However, the development of acute liver failure is rare in patients with $\mathrm{AL}$. In fact, the incidence of acute

(c) 2014 Parikh et al; licensee Herbert Publications Ltd. This is an Open Access article distributed under the terms of Creative Commons Attribution License (http://creativecommons.org/licenses/by/3.0). This permits unrestricted use, distribution, and reproduction in any medium, provided the original work is properly cited. 
Parikh et al. Internal Medicine Inside 2014,

liver failure in patients with any infiltrating malignancy, such as $\mathrm{MM}$, is less than 1\% [7]. Here, we report an unusual case of hepatic amyloidosis presenting as acute liver decompensation resulting in death.

\section{Case presentation}

A 76 year old man presented to a community hospital with a six month history of progressive weakness and anorexia resulting in weight loss. The patient had a past medical history significant for a left pontine stroke one year prior to presentation and had since been on atorvastatin and clopidogrel. At the onset of the patient's symptoms of weakness and anorexia, laboratory results were significant for an alkaline phosphatase (ALP) of $300 \mathrm{u} / \mathrm{l}$. At that time, the atorvastatin was discontinued. The patient's symptoms of fatigue and weight loss persisted and he eventually developed abdominal distention, prompting the patient to seek further care. On admission to the hospital, his laboratory results were notable for ALP $948 \mathrm{u} / \mathrm{l}$, total bilirubin $3.8 \mathrm{mg} / \mathrm{dl}$, aspartate aminotransferase (AST) $150 \mathrm{u} / \mathrm{l}$, and alanine aminotransferase (ALT) $130 \mathrm{u} / \mathrm{l}$.

Liver ultrasound (without duplex imaging) was normal. Markers for Hepatitis B, Hepatitis C, Hepatitis E, and Hepatitis A were negative. Further work-up including CA 19-9, antinuclear antibody, anti-smooth muscle antibody, anti-mitochondrial Ab, cytomegalovirus titer, and Epstein barr virus titers were normal. Magnetic resonance cholangiopancreatography (MRCP) was normal as well. A diagnostic paracentesis was performed, with labs reported normal except for an ascitic albumin of $0.3 \mathrm{~g} /$ $\mathrm{dl}$. The patient was discharged with a diagnosis of presumed drug-induced liver injury. After discharge, the patient developed recurrent ascites and within the following week, sought a second opinion at a tertiary hospital. Upon admission there, initial laboratory abnormalities included creatinine $1.32 \mathrm{mg} /$ dL, total bilirubin 6.9 mg/dl, AST 134 u/l, ALT 68 u/l, ALP 1026 $\mathrm{u} / \mathrm{l}$, internationalized normalized ratio (INR) 1.26 , and platelet count 271,000. On exam, the patient was cachectic and jaundiced, with scleral icterus and abdominal distention. Liver ultrasound with doppler imaging was significant for increased echogenicity of the liver with residual ascites present. On day 4 of the admission, a transjugular liver biopsy was performed, which was significant for massive amyloid deposition in the liver; the deposits were positive for amyloid birefringence and generic amyloid protein P (Figures 1 and 2). Additionally, lambda light chain restriction was noted within the amyloid as well. These findings, as well as laboratory results significant for elevated immunoglobulin (Ig) A, decreased IgG and IgM, renal disease, significant, elevated beta-microglobulin, and urine protein electrophoresis showing monoclonal IgA lambda, suggested a diagnosis of hepatic amyloid secondary to MM.

The liver biopsy also identified elevated portal pressures and therefore, the patient underwent an esophagogastroduodenoscopy (EGD), demonstrating esophageal varices, which were banded, and gastric erythema. Biopsies from the EGD were significant focal amyloid deposits. Transthoracic

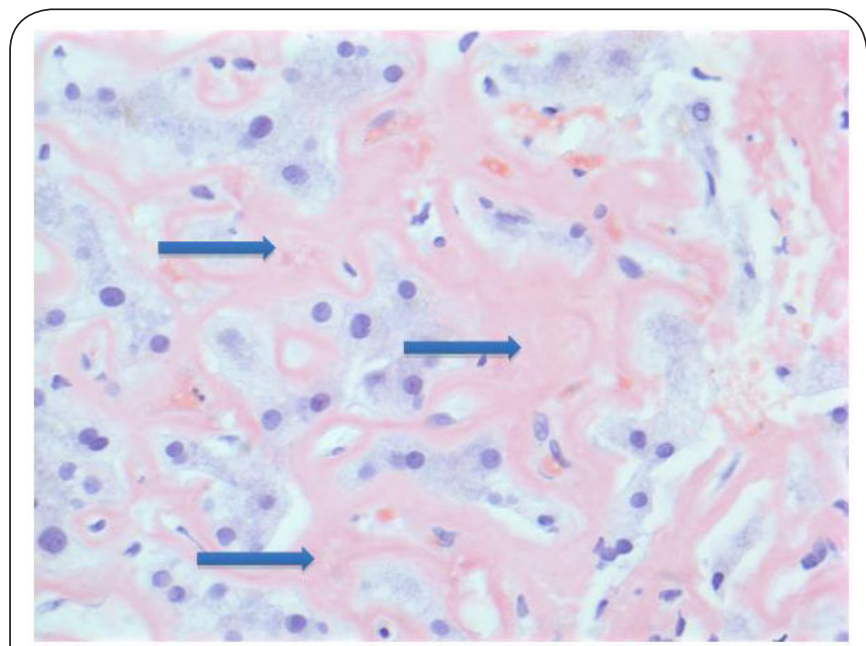

Figure 1. Congo red staining of liver tissue. Arrows depict amyloid deposition.

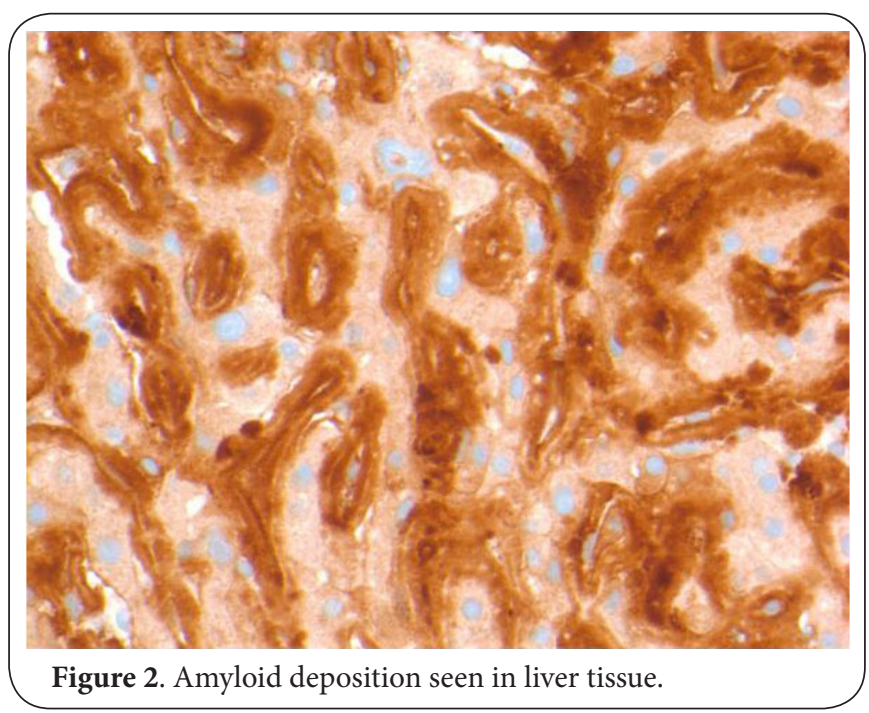

echocardiogram (TTE) was suspicious for cardiac amyloid given the sparkly appearance of the myocardium and biventricular hypertrophy. On day 5 of the hospitalization, the patient's disease acutely worsened with AST increasing from 98 to $1043 \mathrm{u} / \mathrm{l}$ and ALT increasing from 48 to $436 \mathrm{u} / \mathrm{l}$; transaminases eventually peaked to AST $3362 \mathrm{u} / \mathrm{l}$, ALT 1439 $\mathrm{u} / \mathrm{l}$, and total bilirubin $18.8 \mathrm{mg} / \mathrm{dl}$. Work-up during this development of acute liver failure remained nondiagnostic as imaging and laboratory tests were not suggestive of triggering factors such as portal vein thrombosis or intraabdominal bleeding as a complication of the recent liver biopsy. Additionally, cardiovascular compromise, infectious etiologies, and toxins were ruled out. Unfortunately, given the acute hepatic decompensation including development of encephalopathy on day 8 of admission, the patient was not a candidate for chemotherapy. The patient was started on Lactulose and $\mathrm{N}$-acetylcysteine (NAC) though his mental 
status continued to worsen. patient died on day 10 of the admission from multi-organ compromise secondary to acute liver failure.

\section{Discussion}

Amyloidosis and MM resulting in hepatic failure has previously been reported but remains quite rare $[7,8]$. Only a few case reports in the past few years have been able to successfully touch on the rarity of our patient's presentation of acute liver failure in the face of newly diagnosed amyloidosis and MM [12-15]. More importantly, these cases have highlighted the rapid decline associated with acute liver failure in these patients. However, even without the complication of liver failure, patients with hepatic amyloid deposition secondary to systemic AL carry a poor prognosis. One study, consisting of 130 patients, demonstrated that 5-year survival decreased from $72 \%$ to $43 \%$ when liver involvement of amyloid was noted [16]. Elevated bilirubin and cardiac involvement are also predictors of poor prognosis, both of which are pertinent to our case as well [17].

In our case, the patient did not exhibit the common signs and symptoms of MM, which would have prompted an earlier diagnosis. Similarly, a study of 98 patients with hepatic dysfunction showed that a diagnosis of plasma cell dyscrasia, such as MM or AL, was only considered in $26 \%$ of patients at time of presentation [1]. Markers such as elevated CRP, decreased albumin, and increased formation of the globular form of amyloidosis are currently being studied as predictors of hepatic involvement in AL patients $[18,19]$. Moreover, treatment of MM patients with significant hepatic dysfunction is challenging because most chemotherapy agents cannot be delivered in the setting of acute liver failure due to liver toxicity, as was a limitation in our patient's case.

Another consideration in our case was the timing of acute liver failure development during the patient's hospital admi-ssion. The onset of acute liver failure began the day following the patient undergoing transjugular liver biopsy. While this may have been coincidental, complications from the procedure causing acute liver failure were considered. A higher incidence of bleeding following liver biopsy in hepatic amyl-oidosis has been documented in the past [1]. Large controlled trials have yet to evaluate the connection between liver biopsy and amyloidosis though a small case series in the 1960s did mention the potential risk for bleeding [22]. In fact, recent research has emphasized the increased risk of bleeding from liver biopsy in patients with amyloid deposition though the transjugular approach has decreased such risks when compared to the percutaneous method [23,24]. Additionally, portal hypertension in the setting of hepatic amyloidosis can lead to severe complications, including subcapsular hematoma and spontaneous rupture of the liver $[25,26]$. While the above possibilities were thoroughly considered as the source of our patient's decompensation, the work-up during the transition to acute liver failure remained unrevealing.

\section{Conclusions}

Clinicians must consider infiltrative diseases, such as MM and amyloidosis, when patients present with an extended prodromal illness paired with unexplained, worsening hepatic dysfunction. Additionally, patients who present with AL are at high risk for rapid clinical deterioration. To optimize the approach in managing future cases of liver involvement in amyloidosis and MM, a standardized diagnostic and therapeutic plan needs to be formulated so to avoid the development of acute liver failure.

\section{Practice points}

1. Infiltrative diseases, such as multiple myeloma and amyloidosis, are important to consider when patient's present with non-specific symptoms and abnormal liver function tests.

2. Amyloidosis often presents in association with multiple myeloma, which is commonly referred to as primary amyloidosis.

3. The most common presentation of hepatic amyloidosis involves hepatomegaly, generalized fatigue, and labs suggestive of cholestatic hepatitis.

4. In the setting of acute liver failure, etiologies such as toxins and cardiovascular compromise must be ruled out.

5. Complications of transjugular liver biopsy include intra abdominal bleeding, which can result in acute liver failure and systemic decompensation in patients.

6. Hepatic involvement in patients with amyloidosis or multiple myeloma is often an indicator of poor prognosis.

7. Multiple myeloma is often diagnosed only after the diagnosis of amyloidosis has been established.

8. Treating patients with multiple myeloma and hepatic involvement is high risk given the significant liver toxicity caused by several chemotherapy options.

\section{Competing interests}

The authors declare that they have no competing interests.

Authors' contributions

\begin{tabular}{|l|c|c|}
\hline Authors' contributions & RP & CST \\
\hline Research concept and design & $\checkmark$ & $\checkmark$ \\
\hline Collection and/or assembly of data & $\checkmark$ & $\checkmark$ \\
\hline Data analysis and interpretation & $\checkmark$ & $\checkmark$ \\
\hline Writing the article & $\checkmark$ & $\checkmark$ \\
\hline Critical revision of the article & $\checkmark$ & $\checkmark$ \\
\hline Final approval of article & $\checkmark$ & $\checkmark$ \\
\hline Statistical analysis & $\checkmark$ & $\checkmark$ \\
\hline
\end{tabular}

Publication history

EIC: Fabio Angeli, University of Perugia, Italy. Received: 24-Sep-2014 Final Revised: 22-Oct-2014

Accepted: 22-Nov-2014 Published: 29-Nov-2014 
Parikh et al. Internal Medicine Inside 2014,

http://www.hoajonline.com/journals/pdf/2052-6954-2-5.pdf

doi: $10.7243 / 2052-6954-2-5$

\section{References}

1. Park MA, Mueller PS, Kyle RA, Larson DR, Plevak MF and Gertz MA. Primary $(\mathrm{AL})$ hepatic amyloidosis: clinical features and natural history in 98 patients. Medicine (Baltimore). 2003; 82:291-8. I Article I PubMed

2. Perez-Soler R, Esteban R, Allende E, Tornos Salomo C, Julia A and Guardia J. Liver involvement in multiple myeloma. Am J Hematol. 1985; 20:25-9. | Article | PubMed

3. Arebi N, Patel B, Aqel NM and Pitcher MC. IgA multiple myeloma presenting as non-obstructive jaundice. Postgrad Med J. 2004; 80:48990. | Article | PubMed Abstract | PubMed Full Text

4. Bell HG, David R and Shamsuddin AM. Extrahepatic biliary obstruction and liver failure secondary to myeloma of the pancreas. Hum Pathol. 1982; 13:940-2. | Article | PubMed

5. Abu-Hammour AM, Venu RP, Etzkorn KP, Showel JL, Zaytsev PM and Brown RD. Common bile duct obstruction caused by multiple myeloma of the pancreas. Gastrointest Endosc. 1996; 44:606-8. | Article | PubMed

6. Segev A, Manor Y, Bernheim J and Mekori YA. Light chain myeloma presenting as severe obstructive jaundice due to hepatic amyloidosis. Eur J Haematol. 1999; 63:364-5. | Article | PubMed

7. Rowbotham D, Wendon J and Williams R. Acute liver failure secondary to hepatic infiltration: a single centre experience of 18 cases. Gut. 1998; 42:576-80. | Article I PubMed Abstract | PubMed Full Text

8. Yamamoto $\mathrm{T}$, Maeda $\mathrm{N}$ and Kawasaki $\mathrm{H}$. Hepatic failure in a case of multiple myeloma-associated amyloidosis (kappa-AL). J Gastroenterol. 1995; 30:393-7. | Article | PubMed

9. Kapadia SB. Multiple myeloma: a clinicopathologic study of $\mathbf{6 2}$ consecutively autopsied cases. Medicine (Baltimore). 1980; 59:380-92. | Article | PubMed

10. Kyle RA. Multiple myeloma: review of 869 cases. Mayo Clin Proc. 1975; 50:29-40. | Article | PubMed

11. Michopoulos S, Petraki K, Petraki C and Dimopoulos MA. Light chain deposition disease of the liver without renal involvement in a patient with multiple myeloma related to liver failure and rapid fatal outcome. Dig Dis Sci. 2002; 47:730-4. | Article | PubMed

12. Berrios M, Armas-Merino R, Franco C, Parrochia E and Wolff C. [Acute Liver Failure in patient with liver amyloidosis associated to multiple myeloma]. Rev Med Chil. 2003; 131:1301-4. I Article I PubMed

13. Mena-Duran A, Munoz Vicente E, Pareja Llorens G and Sanchis Cervera J. Liver failure caused by light chain deposition disease associated with multiple myeloma. Intern Med. 2012; 51:773-6. I Article I PubMed

14. Cross TJ, Wendon JA, Quaglia A, Salisbury JR, Heneghan MA and Harrison PM. Myeloma associated amyloidosis presenting as subacute liver failure. Postgrad Med J. 2006; 82:e13. | Article | PubMed Abstract | PubMed Full Text

15. Barth C, Bosse A and Andus T. Severe acute cholestatic hepatitis by infiltration of monoclonal plasma cells in multiple myeloma. $Z$ Gastroenterol. 2005; 43:1129-32. | Article I PubMed

16. Lovat LB, Persey MR, Madhoo S, Pepys MB and Hawkins PN. The liver in systemic amyloidosis: insights from 123 l serum amyloid $P$ component scintigraphy in 484 patients. Gut. 1998; 42:727-34. | Article | PubMed Abstract I PubMed Full Text

17. Lloreta J, Vadell C, Fabregat $X$ and Serrano S. Fibrolamellar hepatic tumor with neurosecretory features and systemic deposition of AA amyloid. Ultrastruct Pathol. 1994; 18:287-92. I Article I PubMed

18. Jeong $\mathrm{HJ}$, Hahn EK, Kim E and Park Cl. Hepatic amyloidosis--two cases report. J Korean Med Sci. 1988; 3:151-5. | Article | PubMed Abstract | PubMed Full Text

19. Makhlouf HR and Goodman ZD. Globular hepatic amyloid: an early stage in the pathway of amyloid formation: a study of 20 new cases. Am J Surg Pathol. 2007; 31:1615-21. | Article | PubMed

20. Trojan A, Chasse E, Gay B, Pichert G and Taverna C. Severe hepatic toxicity due to thalidomide in relapsed multiple myeloma. Ann Oncol. 2003; 14:501-2. | Article | PubMed

21. Rosinol L, Montoto S, Cibeira MT and Blade J. Bortezomib-induced severe hepatitis in multiple myeloma: a case report. Arch Intern Med. 2005; 165:464-5. | Article | PubMed

22. Winkler DD, Emery JA and Alan CB. Amyloidosis of the endometrium: an asymptomatic presentation. Obstet Gynecol. 2004; 104:1144-7. I Article I PubMed

23. Joseph $M$ and Cross TJ. Amyloidosis and subacute liver failure. Gastroenterol Hepatol (N Y). 2012; 8:208-11. | PubMed Abstract | PubMed Full Text

24. Kalambokis G, Manousou P, Vibhakorn S, Marelli L, Cholongitas E, Senzolo $\mathrm{M}$, Patch D and Burroughs AK. Transjugular liver biopsy--indications, adequacy, quality of specimens, and complications--a systematic review. J Hepatol. 2007; 47:284-94. | Article | PubMed

25. Lehmann TG, Scheble V, Miller S, Heininger A, Fend F and Koenigsrainer A. Spontaneous hepatic rupture in amyloidosis - report of a case. $Z$ Gastroenterol. 2012; 50:1296-301. | Article | PubMed

26. Bujanda L, Beguiristain A, Alberdi F, Cosme A, Ruiz de la Hermosa J, Gutierrez $S$ and Arenas JI. Spontaneous rupture of the liver in amyloidosis. Am J Gastroenterol. 1997; 92:1385-6. | Article I PubMed

\section{Citation:}

Parikh R and Tsai CS. Amyloidosis presenting as acute liver failure: a case report. Intern Med Inside. 2014; 2:5. http://dx.doi.org/10.7243/2052-6954-2-5 